\title{
Pengaruh Sikap dan Sosial Budaya terhadap Kejadian Unmet Need pada WUS
}

\author{
Latifah Hanum
}

Fakultas IImu Kesehatan Universitas Islam Jember e-mail : latifahh59@gmail.com

\begin{abstract}
Abstrak
KB adalah kebutuhan pemakaian kontrasespsi yang tidak terpenuhi. Wanita usia reproduktif yang tidak memakai kontrasepsi apabila ingin mengatur jarak kehamilan dan tidak menginginkan hamil lagi dalam waktu dua tahun yang akan datang dan tidak memakai KB. Tujuan dari penelitian ini yaitu pengaruh sikap dan sosial budaya terhadap kejadian unmet need pada WUS di kabupaten Jember. Desain yang diteliti akan memakai analitik observasional yaitu desain penelitian Cross sectional. Sebagian responden akan diambil dan diteliti yaitu 382 Wanita pasangan usia subur. data penelitian ini menggunakan Regresi logistic. Teknik pengambilan sampel pada penelitian ini mengunakan tehnik multistage random sampling. Hasil yang akan diteliti menghasilkan dan didapatkan bahwa terdapat pengaruh sikap dan sosial budaya pada kejadian unmet need pada WUS. sikap, memiliki nilai $(p=0.000)$, sosial budaya yaitu nilai $(p=0.000)$.
\end{abstract}

Kata Kunci: Sikap, dan Sosial Budaya

\begin{abstract}
Unmet need Contraception is a requirement of contraception that doesn't met. It can be called unmet need women of childbeaving age if they want to delay, or stop the next pregnancy for two years later, but they don't use contraception. The purpose of this research is. about the influence of attitude and socio cultural Sub. Districts Jember. The research design used an observasional analysis with cross sectional design. The sample used in this research was 382 women of fertile couples. This research data used logistic regression. Sampling technique in this research used multistage random sampling technique. The results showed that there was attitude and sicio culture on unmet need contraception knowledge with the value $(p=0.000)$, attitude and socio cultural with the value $(p=0.000)$
\end{abstract}

Key words: Keywords: Unmet need contraseptions attitude and socio cultural

\section{Pendahuluan}

Pertumbuhan penduduk yang semakin banyak menjadi masalah besar bagi Indonesia.. Indonesia adalah salah satu negara berkembang yang sekarang mempunyai masalah pertumbuhan penduduk. Penduduk yang meningkat Indonesia di tahun 2015 dengan jumlah 255,5 juta jiwa yaitu dengan peningkatan jumlah penduduk sebanyak $1,38 \%$, padahal angka idealnya dibawah 1 persen. hal ini memerlukan solusi dari pemerintah dengan mengurangi jumlah penduduk yaitu mengatur jarak dan jumlah anak dengan kontrasepsi (Febrina, 2017).

Jumlah KB yang tidak terpenuhi di Kabupaten Jember tahun 2015 sebanyak 10,4 $\%$ angka ini kurang memenuhi target RPJMN 2014 yaitu kurang dari $5 \%$. Sedangkan di tahun 2016 sebesar 9,33\% (45.124) (DP3AKB Jember, 2016). Kecamatan Sumberjambe adalah kecamatan paling banyak jumlah KB yang tidak terpenuhi terbanyak di semua kecamatan di Kabupaten Jember pada tahun 2015. Angka unmet need KB nya yaitu 15 persen atau 2.732 pasangan usia subur (PUS) dengan rincian menunda anak (IAT) sebanyak 1.307 PUS dan tidak memiliki keturunan lagi (TIAL) sebanyak 1.425 PUS (Thohirun et al., 2017).

Faktor penyebab tingginya KB yang tidak terpenuhi pada wanita usia reproduktif adalah melalui pendekatan teori Green (1980) yaitu mengatakan sikap adalah pemanfaatan pelayanan kesehatan yang disebabkan beberapa faktor, yakni sikap dan sosial budaya.

Solusi mengurangi kontrasepsi yang tidak terpenuhi dan jumlah yang berhenti memakai kontrasepsi adalah dengan peningkatan pergerakkan lini di masyarakat. Hal ini didukung hasil penelitin yang dilakukan oleh Rismawati, 2016, yaitu mengikutsertakan instansi penduduk dii desa dan di kota yang paling utama yaitu petugas lapangan khusus kontrasepsi, pihak yang dekat dengan masyarakat harus selalu merangkul dengan pihak manapun untuk dipersiapkan bahan konseling (Komunikasi, Informasi dan Edukasi) yaitu dengan mendidik pasangan usia subur untuk memiliki rencana bagi keluarganya dan ditiap tahapan layanan harus memakai percakapan, mendapat info terkini kontrasepsi dan pembelajaran sehingga merubah pola pikir masyarakat bahwa pilihan memakai kontrasepsi adalah hal yang tepat dan diinginkan.

Pertumbuhan penduduk yang semakin banyak menjadi masalah besar bagi Indonesia.. Indonesia adalah salah satu negara berkembang yang sekarang 
mempunyai masalah pertumbuhan penduduk. Penduduk yang meningkat Indonesia di tahun 2015 dengan jumlah 255,5 juta jiwa yaitu dengan peningkatan jumlah penduduk sebanyak 1,38\%, padahal angka idealnya dibawah 1 persen. hal ini memerlukan solusi dari pemerintah dengan mengurangi jumlah penduduk yaitu mengatur jarak dan jumlah anak dengan kontrasepsi (Febrina, 2017).

Jumlah KB yang tidak terpenuhi di Kabupaten Jember tahun 2015 sebanyak 10,4 $\%$ angka ini kurang memenuhi target RPJMN 2014 yaitu kurang dari $5 \%$. Sedangkan di tahun 2016 sebesar 9,33\% (45.124) (DP3AKB Jember, 2016). Kecamatan Sumberjambe adalah kecamatan paling banyak jumlah KB yang tidak terpenuhi terbanyak di semua kecamatan di Kabupaten Jember pada tahun 2015. Angka unmet need KB nya yaitu 15 persen atau 2.732 pasangan usia subur (PUS) dengan rincian menunda anak (IAT) sebanyak 1.307 PUS dan tidak memiliki keturunan lagi (TIAL) sebanyak 1.425 PUS (Thohirun et al., 2017). Faktor penyebab tingginya KB yang tidak terpenuhi pada wanita usia reproduktif adalah melalui pendekatan teori Green (1980) yaitu mengatakan sikap adalah pemanfaatan pelayanan kesehatan yang disebabkan beberapa faktor, yakni sikap dan sosial budaya.

Solusi mengurangi kontrasepsi yang tidak terpenuhi dan jumlah yang berhenti memakai kontrasepsi adalah dengan peningkatan pergerakkan lini di masyarakat. $\mathrm{Hal}$ ini didukung hasil penelitin yang dilakukan oleh Rismawati, 2016, yaitu mengikutsertakan instansi penduduk dii desa dan di kota yang paling utama yaitu petugas lapangan khusus kontrasepsi, pihak yang dekat dengan masyarakat harus selalu merangkul dengan pihak manapun untuk dipersiapkan bahan konseling (Komunikasi, Informasi dan Edukasi) yaitu dengan mendidik pasangan usia subur untuk memiliki rencana bagi keluarganya dan ditiap tahapan layanan harus memakai percakapan, mendapat info terkini kontrasepsi dan pembelajaran sehingga merubah pola pikir masyarakat bahwa pilihan memakai kontrasepsi adalah hal yang tepat dan diinginkan.

\section{Metode Penelitian}

Desain penelitian yang digunakan yaitu Cross sectional. Jumlah sebagian populasi akan diambil yaitu 382 Wanita usia subur. Untuk mengambil sebagian populasi dengan menggunakan purposive sampling. Tempat yang akan diteliti di Kabupaten jember dengan unmet need terbanyak. Data primer berupa pendidikan, pekerjaan, pengetahuan, sosial budaya, akses pelayanan, kualitas pelayanan, dukungan suami, dukungan petugas dan pemberian KIE memakai angket dan data yang sekunder yaitu dari register KB berupa prosentase unmet need pada wanita usia subur. Uji analisis pengaruh memakai Uji Regresi Logistik dengan multivariate.

\section{Hasil Dan Pembahasan}

Hasil

Menunjukkan bahwa sebagian populasi yang akan diteliti menunjukkan sikap negatif sejumlah 102 responden (49.4\%) unmet need dan sebagian sebagian populasi yang akan diteliti yaitu sikap positif sejumlah 120 responden (68.96\%) tidak unmet need. Hasil analisis data memakai uji regresi logistik menghasilkan signifikansi sebesar 0.000 $(p<0.05)$ yaitu ada pengaruh sikap terhadap unmet need pada WUS. Sikap berpengaruh terhadap unmet need pada WUS nilai $p$ value 0,002 bahwa $\leq 0,05$, mempunyai kesimpulan yaitu faktor sikap ada pengaruh yang erat pada unmet need pada WUS

\section{Pembahasan}

Unmet need adalah kebutuhan wanita reproduktif (WUS) pada kontrasepsi yang tidak ada dan akhirnya (WUS) menyimpulkan untuk tidak memakai kontrasepsi dan hal yang memungkinkan lagi yaitu kontrasepsi tidak cocok dengan penggunanya. Ada banyak hal yang melatar belakangi masalah tersebut contohnya kurang nyaman dalam pemakaian kontrasepsi, kontrasepsi yang terbatas, kontrasepsi yang tidak tersedia, dan kurang terjangkau biayanya (Listyaningsih 2016). Teori mengemukakan yaitu dengan memberikan layanan pada wanita yang tidak memakai kontrasepsi akan membantu suami istri untuk merencanakan anak yang diinginkannya dan akan meningkatkan ekonominya. Pendapat lain yaitu apabila jumlah kontrasepsi yang tidak terpenuhi menurun akan mengurangi jumlah kematian ibu dan jumlah kematian anak (Uljanah, 2016).

Hasil penelitian sikap sebagian responden mempunyai sikap negatif Menurut Endang (dalam Ekarini, 2008), sebagian yang dekat dengan masyarakat dan pasangan usia subur yang berada di daerah penelitian bisa memahami KB. Dengan alasan, KB yang tidak terpenuhi yaitu efek samping kontrasepsi maupun rasa tidak nyaman memakai kontrasepsi (dalam Budisantoso, 2008). Yaitu mempunyai pendapat bahwa setiap orang 
terlahir yaitu memiliki pandangan dan memiliki rasa, dan terbentuk sepanjang kehidupannya. Manusia memiliki sikap sehingga manusia bisa bertindak dengan khas pada sekitarnya,dan merupakan hasil dari bentuk bersosialisasi. Menurut Gunarsa (1999) sikap seseorang salah satunya adalah pengaruh dari orang lain, dan kemudian keakraban informasi yang lebih banyak sikap kemungkinan akan merubah ataupun tetap, dan perubahan sikap berubah setelah seseorang paham (Susiyanti, 2016).

\section{Kesimpulan Dan Saran}

Kesimpulan

Kesimpulannya adalah dalam penelitian ini yaitu variabel yang berpengaruh terhadap KB yang tidak terpenuhi yaitu sikap dan sosial budaya.

Saran

Kesimpulannya adalah dalam penelitian ini yaitu variabel yang berpengaruh terhadap KB yang tidak terpenuhi yaitu sikap dan sosial budaya.

\section{Daftar Pustaka}

Anugrahah S. 2016. Program KIE (Komunikasi, Informasi, Edukasi), Tingkat pengetahuan wanita usia subur tentang alat kontrasepsi KB IUD. Fakultas IImu Pendidikan, Universitas Negeri Surabaya.

Budisantoso. 2008. Tesis Faktor-Faktor yang Berhubungan dengan Partisipasi Pria dalam Keluarga Berencana di Kecamatan Jetis Kabupaten Bantul Tahun 2008. Semarang: Universitas Diponegoro.

DP3AKB Kabupaten Jember.2017. Pelayanan Kontrasepsi 2016 Kabupaten Jember. Jember: DP3AKB.

Ekarini, S., M.. 2008. Thesis Analisis faktor Yang Berpengaruh terhadap Partisipasi pria dalam KB di Kecamatan Selo Kabupaten Boyolali. Semarang: FKM Universitas Diponegoro.

Febrina D.P, Thohirun, Baroya N. 2017 Hubungan antara Otonomi wanita dan pendapat pada layanan KIE kontrasepsi yaitu KB yang tidak terpenuhi pada wanita usia reproduktif Kabupaten Jember Epidemiologi dan Biostatistika Kependudukan, Fakultas Kesehatan Masyarakat Universitas Jember e-Jurnal Pustaka Kesehatan, Vol. 5, (No. 2). 